\title{
RESPOSTA DE SUÍNOS EM CRESCIMENTO MANTIDOS EM DIFERENTES TEMPERATURAS
}

\author{
RESPONSE OF GROWING SWINE MAINTAINED IN DIFFERENT \\ THERMALENVIRONMENTS
}

\author{
Kiefer, C. ${ }^{1 *}$, B.C.G. Meignen², J.F. Sanches ${ }^{2}$ e A.S. Carrijo ${ }^{1}$ \\ ${ }^{1}$ DZO/FAMEZ/UFMS. Universidade Federal de Mato Grosso do Sul. Av. Senador Filinto Muller, $n^{\circ} 2443$. CEP \\ 79. 070-900. Campo Grande, MS. Brasil. *Correspondência: charles@nin.ufms.br \\ ${ }^{2}$ FAMEZ/UFMS. Brasil.
}

\section{PalaVRas chaVe adicionais}

Ambiente. Bem-estar. Conforto térmico. Estresse por calor.

\section{RESUMO}

Foram utilizados 24 suínos machos castrados, distribuídos em delineamento inteiramente ao acaso composto por dois tratamentos e doze repetições, com o objetivo de avaliar o comportamento, respostas fisiológicas e o desempenho dos animais. As temperaturas médias do período experimental foram $21,5^{\circ} \mathrm{C}$ e $31,3^{\circ} \mathrm{C}$, respectivamente, nos ambientes de conforto térmico e de estresse por calor. Suínos sob estresse por calor permaneceram significativamente menos tempo na posição em pé, mais tempo na posição deitado, menos tempo no comedouro, mais tempo no bebedouro, mais tempo na posição deitado no bebedouro e mais tempo dormindo em relação àqueles mantidos sob conforto térmico. Suínos sob estresse por calor apresentaram consumos de energia, proteína, lisina e ração, ganho de peso e conversão alimentar reduzidos e apresentaram menores pesos de órgãos, exceto do estômago, e freqüência respiratória e temperaturas retal e de superfície aumentadas. Suínos sob conforto térmico apresentaram maior eficiência de utilização da proteína e energia e maiores deposições diárias de proteína e gordura na carcaça. Temperaturas que provocam estresse por calor afetam negativamente o comportamento de suínos em crescimento.

\section{SUMMARY}

Were used 24 castrated swine distributed in completely randomized design composed for two

\section{AdDitional KEYWORDS}

Environment. Welfare. Thermal comfort. Heat stress.

treatments and twelve repetitions, with the objective to evaluate the behavior, physiological responses and the performance of the animals. The average temperatures of the experimental period were $21.5^{\circ} \mathrm{C}$ and $31.3^{\circ} \mathrm{C}$, respectively, in thermal comfort and heat stress. Swine under heat stress remain significantly little time in the position in foot, more time in the lying position, little time in the feeder, more time in the water through, more time in the lying position in the water through and more time sleeping in relation to those kept in thermal comfort. Swine under heat stress had presented energy, protein, lysine and ration intake, weight gain and feed: gain ratio reduced and had presented minor weight of organs, except of the stomach, and had presented increased respiratory frequency and rectal and surface temperatures. Swine under thermal comfort had presented greater efficiency of use of the protein and energy and greater daily protein and fat depositions in the carcass. Temperatures that provoke heat stress affects negatively the behavior of growing swine.

\section{INTRODUÇÃO}

Os suínos têm características comportamentais específicas e são capazes de alterar seu comportamento para se adaptarem ao ambiente em que vivem. Tem-se verificado que em situações de altas temperaturas ambientais os suínos modificam seu 
comportamento alimentar, reduzindo, por exemplo, o número de visitas ao comedouro e o tempo total de ingestão diária de alimento (Quiniou et al., 2000).

Em situações onde há restrição de área física por animal e em que ocorre competição por alimento, os suínos também podem apresentar seu comportamento alimentar modificado o que pode ser determinante para as respostas de desempenho. Tem-se constatado que a redução de área de 0,56 para $0,25 \mathrm{~m}^{2}$ por suíno, na fase de crescimento, reduz o número de visitas diárias ao comedouro e altera o tempo de ingestão de alimento por visita, influenciando negativamente o ganho de peso e a conversão alimentar dos animais (Hyun et al., 1998).

Suínos em ambientes enriquecidos normalmente demonstram evidência comportamental de bem-estar quando comparados com seus pares do confinamento. Beattie et al. (2000) relataram que suínos em ambientes enriquecidos com espaço amplo (inicialmente $1,75 \mathrm{~m}^{2}$ /suíno e posteriormente 3,5 $\mathrm{m}^{2}$ /suíno), piso coberto por palha e várias áreas para acesso utilizaram um quarto de seu tempo em comportamento direcionado para o substrato no piso, enquanto que aqueles animais mantidos em ambiente não enriquecido com espaço reduzido (inicialmente $0,36 \mathrm{~m}^{2} /$ suíno e posteriormente 0,76 $\mathrm{m}^{2}$ /suíno), piso sem palha e sem outras áreas para acesso gastaram mais tempo explorando os objetos fixos da baia e se envolveram mais em comportamentos sociais nocivos, tais como fuçar ou morder o companheiro de baia, do que aqueles no ambiente enriquecido.

Segundo Machado Filho (2000), o ambiente influencia o bem-estar dos suínos. Este pesquisador verificou que leitões, em fase de crescimento, criados em sistema confinado passavam mais tempo desenvolvendo comportamentos anômalos ou agressivos e apresentavam menor freqüência de comportamento alimentar e exploratório do que os criados ao ar livre.

Fatores estressores dentro os quais o confinamento intensivo, isolamento social, ausência de substrato, fome, alta densidade e a baixa qualidade do ar podem levar os animais a redirecionar o seu comportamento natural para vícios, estereótipos ou comportamentos anômalos (Machado Filho e Hötzel, 2000) e esses fatores podem prejudicar o desempenho dos suínos. A redução de comportamentos anti-sociais proporcionada pelo enriquecimento ambiental e pela maior área disponível por animal pode melhorar o consumo de alimento, ganho de peso, conversão alimentar, peso ao abate e o peso das carcaças (Beattie et al., 2000).

Além dos efeitos negativos sobre o desempenho, os fatores estressores estão relacionados com problemas de má qualidade de carne, principalmente com o aumento da freqüência de ocorrência de carne DFD (escura, dura e seca) (Warris et al., 1998) e ao aumento da incidência de doenças observada em sistemas confinados (Rollin, 1995).

Dentre os estressores ambientais, a temperatura do ar tem sido citada como fator que pode alterar a fisiologia do suíno (Oliveira, 1996), o consumo de alimentos (Edmonds et al., 1998), a eficiência de utilização do alimento, a composição de carcaça e os pesos dos órgãos (Tavares et al., 2000). Temperaturas ambientais elevadas podem reduzir a concentração de hormônios tireoidanos no soro, reduzindo a atividade metabólica de órgãos como o fígado, rins e intestinos que são os responsáveis por grande parte da produção de calor corporal (Koong et al., 1983). Além disso, temperaturas ambientais elevadas podem aumentar a frequência respiratória (Manno et al., 2006) que é um dos mecanismos mais eficientes para perda de calor corporal pelo suíno para manutenção da homeostase térmica (Christon, 1988).

Desta forma, este estudo tem como objetivo avaliar os efeitos da temperatura do ar sobre o comportamento, respostas fisiológicas e desempenho de suínos na fase de crescimento.

Archivos de zootecnia vol. 58, núm. 221, p. 56. 


\section{MATERIALE MÉTODOS}

Foram utilizados 24 suínos machos castrados, obtidos do cruzamento entre Landrace $\mathrm{x}$ (Landrace $\mathrm{x}$ Large White), alojados em sala climatizada e mantidos em gaiolas metálicas suspensas, com pisos e laterais teladas, providas de comedouro semi-automático e bebedouro automático tipo chupeta.

Os animais foram distribuídos em delineamento inteiramente ao acaso, composto por dois tratamentos (ambiente de conforto térmico, $21^{\circ} \mathrm{C}$ e ambiente de estresse por calor, $31^{\circ} \mathrm{C}$ ), doze repetições, sendo cada unidade experimental constituída por um animal.

O peso inicial dos animais foi de $30,1 \pm 1,79$ $\mathrm{kg}$ e $30,9 \pm 2,09 \mathrm{~kg}$, respectivamente, para o ambiente de conforto térmico e de estresse por calor. Os animais permaneceram sob observação até atingirem o peso de $60,8 \pm 4,40$ $\mathrm{kg}$ e $59,7 \pm 3,72 \mathrm{~kg}$, respectivamente, no ambiente de conforto térmico e de estresse por calor.

Durante o período experimental os animais foram alimentados com a mesma dieta, formulada a base de milho, sorgo e farelo de soja, suplementada com aminoácidos sintéticos, minerais e vitaminas de modo a atender as exigências nutricionais (Rostagno et al., 2000).

A temperatura interna da câmara climática foi mantida constante por meio de equipamentos de aquecimento e refrigeração controlados por um termostato regulado para a temperatura de $21^{\circ} \mathrm{C}$ (conforto térmico) e de $31^{\circ} \mathrm{C}$ (estresse por calor).

Em uma gaiola vazia no centro da câmara climática a uma altura correspondente à meia altura dos animais foi instalado um conjunto de termômetros (bulbo seco, bulbo úmido e globo negro) utilizados para a medição das temperaturas ambientais. As leituras dos termômetros foram realizadas diariamente às 08:00 e às 16:00 horas.

Os valores de temperatura de bulbo seco, bulbo úmido e globo negro registrados durante o período experimental foram, posteriormente, convertidos no índice de temperatura de globo e umidade (ITGU), segundo Buffington et al. (1981), e este índice foi utilizado para caracterizar o ambiente térmico, no qual os animais foram mantidos durante o período experimental.

A cada cinco dias foram medidas as temperaturas de superfície e a temperatura retal dos animais, pela manhã (08:00 horas) e à tarde (15:00 horas), e realizada a contagem da freqüência respiratória às 08:00 horas. As temperaturas de superfície foram medidas por meio de um termômetro a laser sendo medidas na nuca, paleta e pernil, previamente depiladas, enquanto a temperatura retal foi medida por meio de um termômetro clínico durante um minuto. A freqüência respiratória foi obtida por meio da contagem dos movimentos do flanco dos animais em descanso durante um minuto.

Para a avaliação das atividades comportamentais, foram observados 24 suínos, sendo 12 no ambiente de conforto térmico e 12 no ambiente de estresse por calor. Os animais foram observados em dias alternados. As observações do comportamento foram realizadas por quatro observadores, em sistema de revezamento, entre às 7:00 e às 19:00 horas, perfazendo um total de 12 horas em cada período de observação. As observações foram realizadas em período integral, com auxílio de relógios digitais, onde o início de uma atividade determinou o fim da anterior.

Foram observadas as seguintes atividades comportamentais: ócio na posição em pé, ócio na posição deitado, animal consumindo alimento, animal acionando bebedouro na posição em pé, animal acionando bebedouro na posição deitado, animal fuçando na posição em pé, animal fuçando na posição deitado e animal dormindo.

Para a determinação das variáveis de desempenho foram pesadas as quantidades fornecidas e as sobras de ração dos comedouros ao final do período experimental. 
Ao final do período experimental, após jejum de sólidos de 24 horas, todos os animais foram abatidos por insensibilização e sangria. Após o abate procedeu-se à toalete e abertura da carcaça para a retirada dos órgãos. Os órgãos (fígado, pulmões, estômago, rins, coração, baço e intestino delgado) foram lavados e dependurados a sombra durante 15 minutos para o escorrimento da água. Foram realizados cortes no fígado para melhorar o escorrimento do sangue. Transcorridos 15 minutos, procedeu-se a pesagem dos órgãos e a medição do comprimento do intestino delgado.

Um grupo adicional de cinco suínos, com peso médio de $30,3 \pm 0,94 \mathrm{~kg}$ foi abatido para determinação da composição inicial das carcaças. As deposições de proteína e gordura nas carcaças foram calculadas comparando-se as composições das carcaças dos animais do início com aquelas do final do experimento. As amostras de carcaça pré-secas em estufa de ventilação forçada a $\pm 60^{\circ} \mathrm{C}$, por 96 horas, foram pré-desengorduradas pelo método a quente no extrator tipo Soxhlet, durante 5 horas, para posterior moagem e análise de gordura e proteína, conforme metodologia descrita por Silva e Queiroz(2002).

As variáveis comportamentais, de desempenho, deposição de proteína e gordura nas carcaças, pesos dos órgãos e os parâmetros fisiológicos obtidos foram submetidos à análise de variância e teste $\mathrm{F}$, por meio do programa estatístico SAS (1996).

\section{RESULTADOSEDISCUSSÃO}

No ambiente de conforto térmico a temperatura média do ar da sala foi de $21,5^{\circ} \mathrm{C}$, a umidade relativa do ar foi de $75,0 \%$, a temperatura de globo negro foi de $21,8^{\circ} \mathrm{C}$ e o ITGU de 69,3. A temperatura média do ar obtida neste estudo pode ser considerada como temperatura termoneutra por estar entre 18 a $26^{\circ} \mathrm{C}$, que é a faixa de temperaturas proposta como ideal para suínos desta categoria (Perdomo, 1994).
Tabela I. Atividades comportamentais, em minutos, de suínos mantidos em diferentes ambientes térmicos na fase de crescimento. (Activities behavior in minutes of swine maintained in different thermal environments on growing phase).

\begin{tabular}{lcccc}
\hline \multicolumn{5}{c}{ Ambiente térmico } \\
& $21^{\circ} \mathrm{C}$ & $31^{\circ} \mathrm{C}$ & $\mathrm{p}<$ & $\mathrm{CV} \%$ \\
\hline Atividades em pé & 205,0 & 167,7 & 0,01 & 10,56 \\
Comendo & 130,5 & 106,6 & 0,01 & 13,31 \\
Bebendo & 23,7 & 25,3 & $\mathrm{NS}$ & 53,12 \\
Ócio & 12,3 & 07,3 & $\mathrm{NS}$ & 12,06 \\
Fuçando & 38,5 & 28,5 & $\mathrm{NS}$ & 54,59 \\
Atividades deitado & 515,0 & 552,3 & 0,01 & 13,75 \\
Dormindo & 281,1 & 308,7 & 0,04 & 11,44 \\
Bebendo & 01,7 & 43,2 & 0,01 & 54,43 \\
Ócio & 162,3 & 141,3 & $\mathrm{NS}$ & 25,01 \\
Fuçando & 69,9 & 59,1 & $\mathrm{NS}$ & 42,13 \\
\hline
\end{tabular}

${ }^{N S}$ Efeito não significativo.

O valor do ITGU que caracterizou o ambiente de conforto térmico está em conformidade com aqueles de 69,1 e de 67,5 obtidos, respectivamente, por Tavares et al. (2000) e Oliveira et al. (2003), para suínos, dos 30 aos $60 \mathrm{~kg}$, mantidos sob temperaturas de conforto térmico.

No ambiente de estresse por calor a temperatura média do ar da sala foi de $31,3^{\circ} \mathrm{C}$, a umidade relativa do ar foi de $72,4 \%$, a temperatura de globo negro foi de $31,3^{\circ} \mathrm{C} \mathrm{e}$ o ITGU foi de 81,7. A temperatura média do ar obtida neste estudo pode ser considerada como temperatura de estresse por calor por estar acima da temperatura crítica máxima de $27^{\circ} \mathrm{C}$, conforme estabelecido por Esmay (1982), citado por Ferreira (2001), para suínos desta categoria.

$\mathrm{O}$ valor de ITGU, que caracterizou o ambiente de estresse por calor está em conformidade com àqueles valores de 81,1 e 82,7 obtidos, respectivamente, por Orlando (2001) e Ferreira (2001), para suínos, dos 30 aos $60 \mathrm{~kg}$, mantidos sob altas temperaturas ambientais.

Os resultados das atividades compor- 
tamentais dos animais em função dos ambientes térmicos estão apresentados na tabela I. O ambiente térmico influenciou $(p<0,01)$ o comportamento dos animais, sendo que os suínos mantidos sob estresse por calor permaneceram menos tempo na posição em pé $(167,7$ x 205,0 $\mathrm{min})$, e, conseqüentemente, mais tempo na posição deitado (552,3 x 515,0 min) em relação aos animais submetidos ao ambiente de conforto térmico.

Dentre as atividades desenvolvidas na posição em pé, observou-se que os animais mantidos no ambiente de estresse por calor permaneceram menos tempo $(\mathrm{p}<0,01)$ comendo (106,6 min) em relação àqueles mantidos sob ambiente de conforto térmico (130,5 min). Resultados similares foram obtidos por Verstegen e Close (1994), que verificaram que suínos mantidos em ambientes com temperaturas elevadas reduziram o consumo em relação àqueles mantidos em conforto térmico.

Não se observou efeito $(p>0,05)$ do ambiente térmico sobre as demais atividades em pé consideradas. Apesar de não ter ocorrido diferença significativa, observouse que o tempo gasto na atividade bebendo em pé foi $6,33 \%$ maior nos animais mantidos em ambiente de calor em relação aos mantidos em conforto térmico.

Com relação às atividades desenvolvidas na posição deitado, observou-se que os animais dormiram na maior parte do tempo avaliado, sendo que os expostos em ambiente de calor passaram mais tempo dormindo $(\mathrm{p}<0,05)$ do que os mantidos em ambiente de conforto (308,7 x 281,1 min).

Da mesma forma, houve diferença $(\mathrm{p}<0,01)$ no tempo que os animais passaram bebendo na posição deitado, onde os animais mantidos sob estresse por calor gastaram 43,2 min e os mantidos em ambiente de calor 1,7 min. Não se observou variação

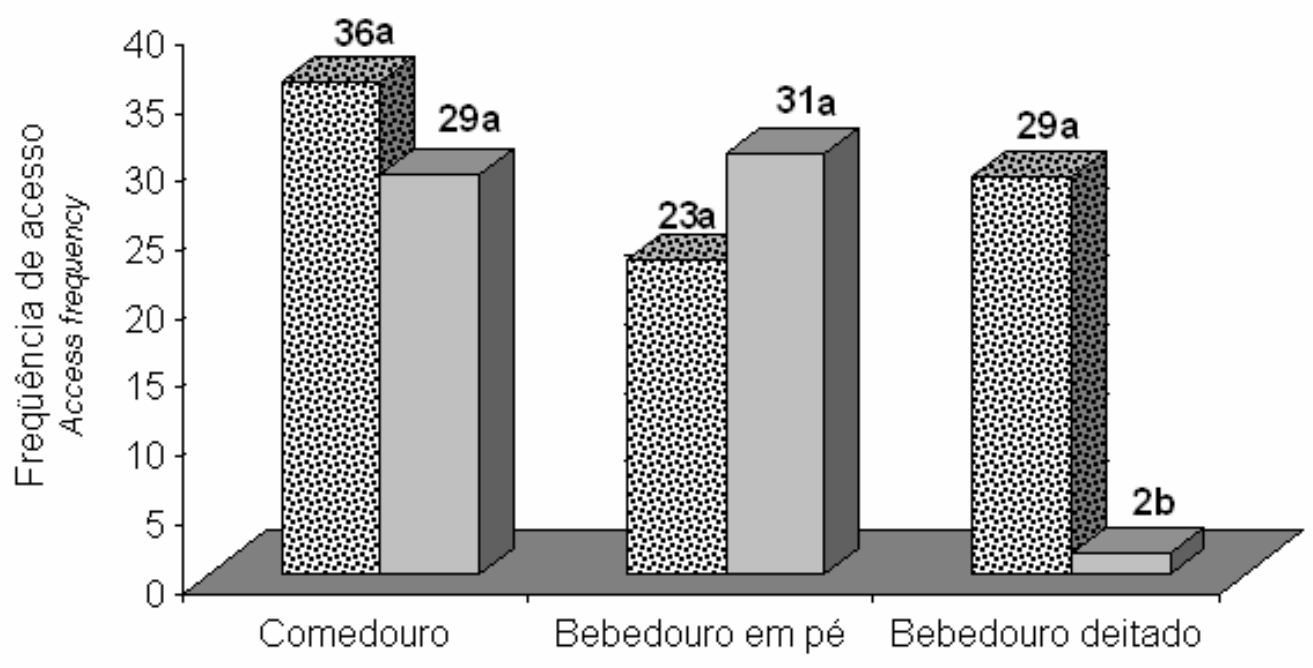

\section{因 $31^{\circ} \mathrm{C} \quad \square 21^{\circ} \mathrm{C}$}

Figura 1. Freqüência de acesso ao comedouro e bebedouro de suínos mantidos em diferentes ambientes térmicos, num período de 12 horas. (Access frequency to the feeder and water through of swine maintained in different thermal environments on a period of 12 hours). 
significativa ( $p>0,05)$, entre os ambientes, nas demais atividades desenvolvidas pelos animais na posição deitado.

De acordo com os resultados obtidos podemos inferir que os animais passaram, em média, apenas $10 \%$ do tempo avaliado em atividade (explorando o ambiente e buscando alimento). Por outro lado, de acordo com Stevenson (2000), em condições naturais, os suínos passam $75 \%$ das horas do dia em atividade (fuçando, buscando alimento e explorando o ambiente). Conforme este pesquisador, a maior parte dos suínos criados em sistemas confinados são alojados em baias não enriquecidas e com alta taxa de lotação, as quais impossibilitam os animais realizarem atividades.

$\mathrm{Na}$ figura 1 estão apresentadas as freqüências de acessos ao comedouro e ao bebedouro. Não houve efeito $(p>0,05)$ do ambiente térmico sobre a freqüência de acesso dos animais ao comedouro e ao bebedouro na posição em pé. Entretanto, a freqüência de acesso dos animais ao bebedouro na posição deitado foi influenciada $(\mathrm{p}<0,05)$ pelo ambiente térmico, sendo que os animais mantidos sob alta temperatura ambiental acionaram o bebedouro com maior freqüência. Este resultado pode ser explicado pela tentativa dos animais de se molharem com o intuito de perder calor por meio da evaporação e, desta forma, amenizar o estresse ambiental.

$\mathrm{Na}$ figura 2 estão apresentados os tempos médios de acessos ao comedouro e ao bebedouro. Não houve efeito $(p>0,05)$ do ambiente térmico sobre o tempo de acesso dos animais ao comedouro. Contudo, a freqüência de acesso dos animais ao bebedouro tanto na posição em pé quanto na posição deitado foram influenciadas $(\mathrm{p}<0,05)$ pelo ambiente térmico, sendo que os animais mantidos sob alta temperatura ambiental permaneceram mais tempo nos

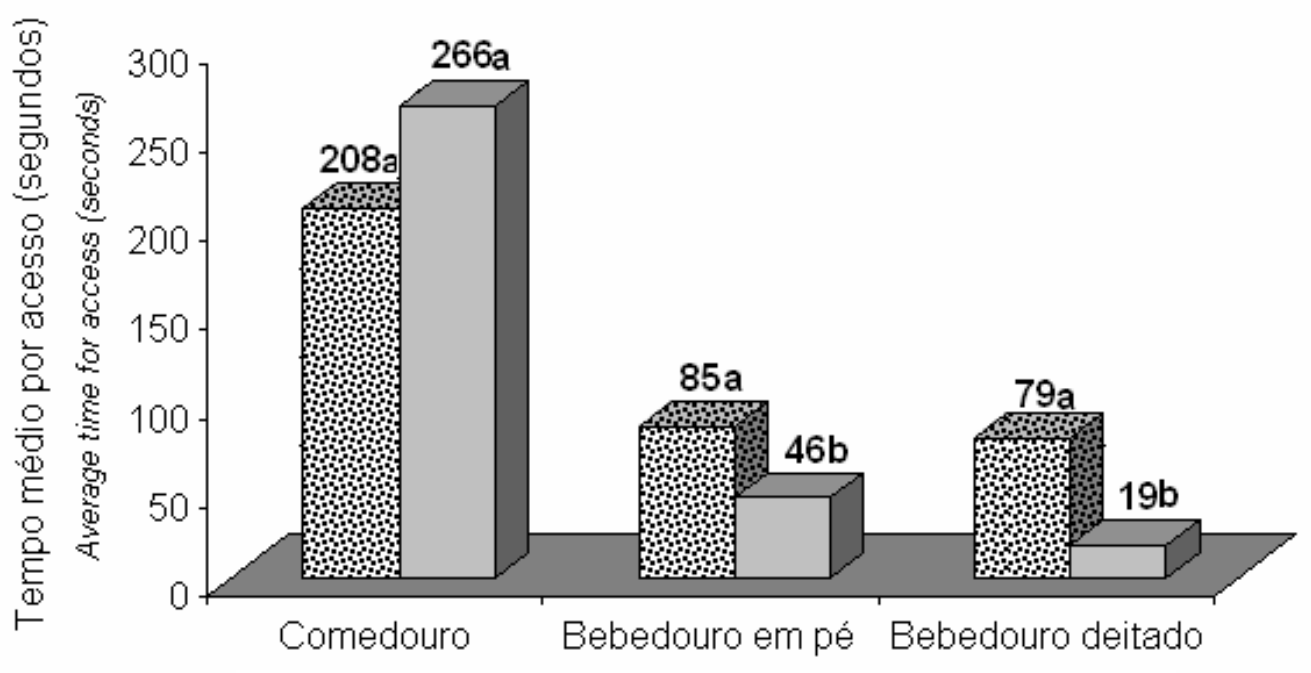

图 $31^{\circ} \mathrm{C} \quad \square 21^{\circ} \mathrm{C}$

Figura 2. Tempo médio por acesso ao comedouro e bebedouro de suínos mantidos em diferentes ambientes térmicos, num periodo de 12 horas. (Average time for access to the feeder and water through of swine maintained in different thermal environments on a period of 12 hours).

Archivos de zootecnia vol. 58, núm. 221, p. 60. 
bebedouros. Este resultado pode ser explicado pelo aumento da exigência diária de água dos animais causada pelas perdas corporais de água, o que está de acordo com NRC(1998).

$\mathrm{Na}$ tabela II estão apresentadas as variáveis fisiológicas. Observou-se aumento $(\mathrm{p}<0,01)$ da freqüência respiratória e das temperaturas retais e de superfície nos suínos mantidos em ambiente quente $\left(31^{\circ} \mathrm{C}\right)$ em relação àqueles mantidos em ambiente de conforto $\left(22^{\circ} \mathrm{C}\right)$. Com relação a temperatura retal, os animais expostos ao ambiente quente apresentaram temperatura média acima da faixa de temperaturas $\left(38,3 \mathrm{a} 39,3^{\circ} \mathrm{C}\right)$ considerada normal para suínos (Andersson e Jónasson, 1993).

Resultados semelhantes de freqüência respiratória foram obtidos por Close (1971), Christon(1988), Lopez et al. (1991) e Oliveira et al. (1997) para suínos em diferentes fases de crescimento. Segundo Christon (1988) e Fialho (1994), o aumento da taxa respiratória propicia aumento na dissipação de calor por evaporação através do trato respiratório dos animais estressados pelo calor, o que associado a outros processos fisiológicos, possibilita a manutenção da homeostase térmica.

Os valores referentes aos pesos dos órgãos e ao comprimento do intestino delgado dos animais são apresentados na

Tabela II. Respostas fisiológicas: freqüência respiratória $(F R)$ e temperatura $\left(T,{ }^{\circ} C\right)$ de suinos mantidos em diferentes ambientes térmicos. (Physiologic responses: respiratory rate (FR) and temperature $\left({ }^{\circ} \mathrm{C}\right)$, of swine maintained in different thermal environments).

\begin{tabular}{lrrrr}
\hline \multicolumn{5}{c}{ Ambiente térmico } \\
& $21^{\circ} \mathrm{C}$ & $31^{\circ} \mathrm{C}$ & $\mathrm{p}<$ & $\mathrm{CV} \%$ \\
\hline FR & 45,90 & 83,53 & 0,01 & 21,49 \\
T. retal & 39,31 & 39,72 & 0,01 & 0,54 \\
T. nuca & 36,24 & 38,75 & 0,01 & 1,36 \\
T. paleta & 36,20 & 38,60 & 0,01 & 1,44 \\
T. pernil & 36,09 & 38,96 & 0,01 & 1,45 \\
\hline
\end{tabular}

Tabela III. Peso (g) de órgãos e comprimento (m) de intestino de suínos mantidos em diferentes ambientes térmicos. (Weight (g) of organs and length $(\mathrm{m})$ of intestine of swine maintained in different thermal environments).

\begin{tabular}{lcccc}
\hline \multicolumn{5}{c}{ Ambiente térmico } \\
& $21^{\circ} \mathrm{C}$ & $31^{\circ} \mathrm{C}$ & $\mathrm{p}<$ & $\mathrm{CV} \%$ \\
\hline Rins & 225 & 199 & 0,01 & 11,32 \\
Fígado & 1180 & 1111 & 0,03 & 9,81 \\
Pulmão & 521 & 454 & 0,04 & 26,54 \\
Baço & 91 & 81 & 0,05 & 25,30 \\
Estômago & 338 & 331 & $\mathrm{NS}$ & 14,28 \\
$\begin{array}{l}\text { Coração } \\
\text { Intestino delgado }\end{array}$ & 218 & 197 & 0,01 & 11,87 \\
$\begin{array}{l}\text { peso } \\
\text { comprimento }\end{array}$ & 1316 & 1216 & 0,01 & 12,72 \\
\hline
\end{tabular}

${ }^{N S E f e i t o ~ n a ̃ o ~ s i g n i f i c a t i v o . ~}$

tabela III. Observou-se redução $(\mathrm{p}<0,01)$ do peso absoluto dos órgãos avaliados, com exceção do estômago, que foram menores nos animais submetidos ao calor.

Resultados similares foram observados em fêmeas com $70 \mathrm{~kg}$ (Lopez et al., 1994), machos castrados dos 40 aos $100 \mathrm{~kg}$ (Nienaber et al., 1996), em leitões dos 15 aos $30 \mathrm{~kg}$ (Oliveira et al., 1997) e em machos castrados dos 30 aos $60 \mathrm{~kg}$ (Tavares et al., 2000). Não foi observado efeito $(p>0,05)$ do ambiente térmico sobre o comprimento do intestino delgado. A redução nos pesos de órgãos dos animais mantidos em ambiente quente, provavelmente, deve-se à tentativa de reduzir a produção de calor pelos órgãos metabolicamente ativos (Zhao et al., 1995).

Os valores de desempenho, eficiência de utilização da energia e da proteína e deposição de gordura e proteína na carcaça dos suínos submetidos aos diferentes ambientes térmicos são apresentados na tabela IV. Os ambientes térmicos influenciaram $(p<0,05)$ o consumo de ração, uma vez que os suínos mantidos sob alta temperatura consumiram cerca de $14,3 \%$ menos alimento que aqueles mantidos sob ambiente de conforto térmico. 
Tabela IV. Desempenho de suínos mantidos em diferentes ambientes térmicos. (Performance of swine maintained in different thermal environments).

\begin{tabular}{|c|c|c|c|c|}
\hline \multicolumn{5}{|c|}{ Ambiente térmico } \\
\hline & $21^{\circ} \mathrm{C}$ & $31^{\circ} \mathrm{C}$ & $p<$ & CV\% \\
\hline Consumo de ração ${ }^{1}$ & 2,12 & 1,81 & 0,03 & 9,79 \\
\hline Ganho de peso ${ }^{1}$ & 1,04 & 0,78 & 0,01 & 10,93 \\
\hline Conversão alimentar ${ }^{2}$ & 2,04 & 2,32 & 0,01 & 4,75 \\
\hline \multicolumn{5}{|l|}{ Consumo de } \\
\hline energia $^{3}$ & 7191 & 6162 & 0,03 & 9,78 \\
\hline proteína $^{4}$ & 328 & 281 & 0,03 & 9,82 \\
\hline lisina digestível ${ }^{4}$ & 17,56 & 15,03 & 0,03 & 9,73 \\
\hline \multicolumn{5}{|l|}{ Eficiência de utilização } \\
\hline Proteína & 3,17 & 2,77 & 0,01 & 3,52 \\
\hline Energia & 0,14 & 0,13 & 0,01 & 3,52 \\
\hline \multicolumn{5}{|l|}{ Deposições na carcaça } \\
\hline Proteína ${ }^{4}$ & 124,85 & 103,34 & 0,01 & 14,39 \\
\hline Gordura ${ }^{4}$ & 228,26 & 177,13 & 0,01 & 15,69 \\
\hline
\end{tabular}

${ }^{1}(\mathrm{~kg} / \mathrm{dia}) ;{ }^{2}(\mathrm{~kg} / \mathrm{kg}) ;{ }^{3}(\mathrm{kcal} / \mathrm{dia}) ;{ }^{4}(\mathrm{~g} / \mathrm{dia})$.

Esse resultado foi semelhante aos encontrados por Le Bellego et al. (2002), que observaram que suínos submetidos a estresse térmico reduziram em torno de $15 \%$ a ingestão diária de alimentos em relação aos animais mantidos em ambiente de conforto $\left(22^{\circ} \mathrm{C}\right)$. Collin et al. (2001), por sua vez, observaram redução mais acentuada no consumo dos animais (30\%) quando a temperatura ambiente foi ajustada para $33^{\circ} \mathrm{C} \mathrm{em}$ relação à de $23^{\circ} \mathrm{C}$. Conforme Manno et al. (2006) a redução do consumo de alimento, provavelmente, é um mecanismo de defesa para minimizar a produção de calor resultante dos processos digestivos e metabólicos, relacionados principalmente à ingestão de alimentos.

Constatou-se que os animais submetidos à alta temperatura ambiente apresentaram redução $(p<0,01)$ de $25,5 \%$ no ganho de peso e piora $(p<0,01)$ de $13,6 \%$ na conversão alimentar em relação aos animais mantidos sob conforto térmico.

Avaliando suínos em crescimento (respectivamente, dos 20 aos $30 \mathrm{~kg}$, e dos 23 aos
$35 \mathrm{~kg}$ ) mantidos em ambiente de estresse por calor (acima de $29^{\circ} \mathrm{C}$ ) em comparação àqueles mantidos em ambiente termoneutro, Collinetal. (2001), Kerretal. (2003) e Manno et al. (2006) também observaram redução no ganho de peso diário e na eficiência alimentar com o aumento da temperatura ambiente.

Contudo, a redução da eficiência de utilização dos alimentos pelos animais mantidos em ambiente quente nem sempre acontece. Oliveira et al. (1997) não encontraram diferenças significativas na eficiência de utilização dos alimentos entre suínos mantidos sob estresse por calor e em conforto térmico. Segundo Kerr et al. (2003), as variações de resultados podem estar associadas à intensidade com que ocorreu a redução na ingestão de alimento.

Por ter ocorrido variação no consumo de alimento entre os ambientes, foi constatado aumento $(\mathrm{p}<0,05)$ do consumo de energia digestível, proteína e lisina digestível dos animais mantidos em ambiente de conforto térmico em relação àqueles mantidos sob alta temperatura.

Quando se analisou a eficiência de utilização da proteína e da energia digestível para ganho, constatou-se que os animais mantidos sob ambiente de conforto térmico foram $14,67 \%$ mais eficientes $(p<0,05)$ na utilização da proteína da dieta $(3,173$ versus $2,767)$ e $14,28 \%$ mais eficientes $(p<0,05)$ na utilização da energia da dieta em relação àqueles mantidos sob estresse térmico $(0,144$ versus 0,126$)$.

Os maiores consumos de energia, proteína e lisina digestível resultaram em maiores $(\mathrm{p}<0,05)$ deposições de proteína e de gordura na carcaça dos animais mantidos sob conforto térmico. Estes resultados são semelhantes aos reportados por Collin et al. (2001), que observaram menor retenção de energia na forma de proteína e gordura em animais com menor consumo de ração em relação àqueles mantidos em ambiente de conforto térmico. Também Manno et al. (2006) observaram redução na deposição diária de proteína e de gordura na carcaça 


\section{SUÍNOS MANTIDOS EM DIFERENTES TEMPERATURAS NA FASE DE CRESCIMENTO}

dos animais submetidos a altas temperaturas ambientais.

Podemos concluir que o estresse por calor provoca distúrbios de comportamento, assim como, afeta negativamente o desempenho (consumo de ração, ganho de peso,

\section{BIBLIOGRAFIA}

Andersson, B.E. e H. Jónasson. 1993. Regulação da temperature e fisiologia ambiental. Em: Swenson, M.J., Reece, W.O. Dukes. Fisiologia dos animais domésticos. Editora Guanabara Koogan S.A. Rio de Janeiro, R.J. p. 681-841.

Beattie, V.E., N.E. O'Connell and B.W. Moss. 2000. Influence of environmental enrichment on the behavior, performance and meat quality of domestic pigs. Livest. Prod. Sci., 65: 71-79.

Buffington, D.E., A. Colazzo-Arocho and G.H. Canton. 1981. Black globe-humidity index (BGHI) as comfort equation for dairy cows. Trans. ASAE, 24: 711-714.

Close, W.H. 1971. The influence of environmental temperature and plane of nutrition on heat losses from individual pigs. Anim. Prod., 13: 295-302.

Christon, R. 1988. The effect of tropical ambient temperature on growth and metabolism in pigs. J. Anim. Sci., 66: 3112-3123.

Collin, A., J. van Milgen, S. Dubois and J. Noblet. 2001. Effect of high temperature and feeding level on energy utilization in piglets. J. Anim. Sci., 79: 1849-1857.

Edmonds, M.S., B.E. Arentson and G.A. Mente. 1998. Effect of protein levels and space allocations on performance of growing-finishing pigs. J. Anim. Sci., 76: 814-821.

Ferreira, R.A. 2001. Avaliação da redução da proteína bruta da ração com suplementação de aminoácidos para suínos dos 15 aos $60 \mathrm{~kg}$ mantidos em diferentes ambientes térmicos. Tese (Doutorado em Zootecnia). Universidade Federal de Viçosa. UFV. Viçosa, MG. 67 p.

Fialho, E.T. 1994. Influência da temperatura ambiental sobre a utilização da proteína e energia em suínos em crescimento e terminação. Em: Simpósio Latino-Americano de nutrição de suínos. Anais... CBNA. São Paulo. p. 63-83.

Hyun, Y., M. Ellis and R.W. Johnson. 1998. Effects of feeder type, space allowance, and mixing on the growth performance and feed intake pattern conversão alimentar) e altera a fisiologia (peso de órgãos, utilização de proteína e de energia e deposições diárias de proteína e de gordura na carcaça, freqüência respiratória e as temperaturas retais e de superfície) dos suínos em fase de crescimento.

of growing pigs. J. Anim. Sci., 76: 2771-2778. Kerr, B.J., J.T. Yen, J.A. Nienaber and R.A. Easter. 2003. Influences of dietary protein level, amino acid supplementation and environment temperature on performance, body composition, organ weights and total heat production of growing pigs. J. Anim. Sci., 81: 1998-2007.

Koong, L.J., J.A. Nienaber and H.J. Mersmann. 1983. Effects of plane of nutrition on organ size and fasting heat production in genetically obese and lean pigs. J. Nutr., 113: 1626-1631.

Le Bellego, I., J. van Milgen and J. Noblet. 2002. Effect of high temperature and low-protein diets on the performance of growing-finishing pigs. J. Anim. Sci., 80: 691-701.

Lopez, J., G.W. Jesse, B.A. Becker and M.R. Ellersieck. 1991. Effects of temperature on the performance of finishing swine. I. Effects of a hot, diurnal temperature on average daily gain, feed intake and feed efficiency. J. Anim. Sci., 69: 1843-1849.

Lopez, J., R.D. Goodband and G.L. Allee. 1994. The effects of diets formulated on an ideal protein basis on growth performance, carcass characteristics, and thermal alance of finishing housed in a hot, diurnal environment. J. Anim. Sci., 72: 367-379.

Machado Filho, L.C.P. 2000. Bem-estar de suínos e qualidade da carne. Uma visão brasileira. Em: I Conferência internacional virtual sobre qualidade de carne suína. Anais... Concórdia. Embrapa Suínos e Aves. 253 p. Documento 69, p. 34-40. Disponível em: www.cnpsa. embrapa.br/sgc/sgc_publicacoes/anais $00 \mathrm{cv}$ portugues.pdf. Acessado em 10/10/2006.

Machado Filho, L.C.P. e M.J. Hötzel. 2000. Bemestar dos suínos. Em: $V$ Seminário internacional de suinocultura. Anais... Gessuli. São Paulo. p. 70-82.

Manno, M.C., R.F.M. de Oliveira, J.L. Donzele, W.P. de Oliveira, R.G.M.V. Vaz, B.A.N. Silva, E.P. 


\section{KIEFER, MEIGNEN, SANCHES E CARRIJO}

Saraiva e K.R.S. Lima. 2006. Efeitos da temperatura ambiente sobre o desempenho de suínos dos 30 aos $60 \mathrm{~kg}$. Rev. Bras. Zootecn., 35: 471477.

Nienaber, J.A., G.L. Hahn, T.P. McDonald and L. Korthals. 1996. Feeding pattern and swine performance in hot environments. Trans. ASAE, 39: 195-202.

NRC. 1998. Nutrients requirements of swine. $10^{\text {th }}$ edition. National Academic of Science. Washington DC. 189 p.

Oliveira, R.F.M., J.L. Donzele e R.T.F. Freitas. 1997. Efeito da temperatura sobre o desempenho e sobre os parâmetros fisiológicos e hormonais de leitões consumindo dietas com diferentes níveis de energia. Rev. Bras. Zootecn., 26: 1174-1182.

Oliveira, R.F.M. 1996. Efeito do nível de energia digestível e da temperatura ambiente sobre o desempenho e sobre parâmetros fisiológicos e hormonal de suínos dos 15 aos $30 \mathrm{~kg}$. Tese (Doutorado em Zootecnia). Universidade Federal de Viçosa. UFV. Viçosa, MG. 139 p.

Oliveira, R.F.M., U.A.D. Orlando e J.L. Donzele. 2003. Níveis de proteína bruta e suplementação de aminoácidos em rações para leitoas mantidas em ambiente termoneutro dos 30 aos $60 \mathrm{~kg}$. Em: Reunião Anual da Sociedade Brasileira de Zootecnia, 40. Anais... Nutrição de não ruminantes. UFSM. Santa Maria.

Orlando, U.A.D. 2001. Nível de proteína bruta da ração e efeito da temperatura ambiente sobre o desempenho e parâmetros fisiológicos de leitoas em crescimento. Tese (Doutorado em Zootecnia). Universidade Federal de Viçosa. UFV. Viçosa, MG. 77 p.

Perdomo, C.C. 1994. Conforto ambiental e produtividade de suínos. Em: Simpósio LatinoAmericano de Nutrição de Suínos, 1994, São Paulo. Anais... CBNA. São Paulo. p. 19-26.

Quiniou, N., S. Dubois and J. Noblet. 2000. Voluntary feed intake and feeding behavior of grouphoused growing pigs are affected by ambient temperature and body weight. Livest. Prod.
Sci., 63: 245-253.

Rollin, B.E. 1995. Farm animal welfare: social, bioethical, and research issues. lowa State University Press. Ames. $168 \mathrm{p}$

Rostagno, H.S., L.F.T. Albino, J.L. Donzele, P.C. Gomes, R.F. Oliveira, D.C. Lopes, A.S. Ferreira e S.L.T. Barreto. 2000. Tabelas brasileiras para aves e suínos. Composição de alimentos e exigências nutricionais. Editora UFV. Viçosa, MG. $141 \mathrm{p}$.

SAS. 1996. SAS User's Guide, version 6, $4^{\mathrm{a}}$ Edition. SAS Institute INC. North Caroline. 1686 p.

Silva, D.J. e A.C. de Queiroz. 2002. Análise de alimentos. Métodos químicos e biológicos. $3^{\mathrm{a}}$ Edição. Editora UFV. Viçosa/MG. 235 p.

Stevenson, P. 2000. Questões de bem-estar animal na criação intensiva de suínos na União Européia. Em: I conferência virtual internacional sobre qualidade de carne suína. Anais... Concórdia. Embrapa Suínos e Aves. 253 p. Documento 69, p. 4-10. Disponível em: www. cnpsa.embrapa.br/sgc/sgc_publicacoes/ anais $00 \mathrm{cv}$ portugues.pdf. Acessado em 10/ 10/2006.

Tavares, S.L.S., J.L. Donzele, R.F.M. Oliveira e A.S. Ferreira. 2000. Influência da temperatura ambiente sobre o desempenho e os parâmetros fisiológicos de suínos machos castrados dos 30 aos 60 kg. Rev. Bras. Zootecn., 29: 199-205.

Verstegen, M.W.A. and W.H. Close. 1994. The environment and the growing pig. In: Cole, D.J.A., Wiseman, J., Varley, M.A. Principles of pig science. Nothingan University. Longhborough. $472 \mathrm{p}$.

Warriss, P.D., S.N. Brown, P. Barton Gade, C Santoqc, L. Nanni Costa, E. Lambooij and R. Geersf. 1998. An analysis of data relating to pig carcass quality and indices of stress collected in the European Union. Meat Sci., 49: 137-144. Zhao, X., H. Jorgensen and B.O. Eggum. 1995. The influence of dietary fiber on body composition, visceral organ weight, digestibility and energy balance in rats housed in different thermal environments. Brit. J. Nutr., 73: 687-699. 